\title{
Improving territorial accessibility of mental health services: The case of Spain
}

\author{
Enrique López-Lara \\ Marco Garrido-Cumbrera \\ M. Pilar Díaz-Cuevas
}

Geography Department. University of Seville

SPAIN

\begin{abstract}
Background and Objectives: Citizens choose their health care services not only depending on their needs, but also on where they are located. The location of the services is especially important in the case of mental health due to the specific features of mental disorders. This article provides an analysis of temporal access by road to outpatient mental health centres in Andalusia (Spain) with a view to improving accessibility for the greatest volume of population possible.

Methods: Firstly, accessibility by road to the outpatient mental health centres was calculated in terms of time by establishing journey times using the ArcGIS Geographical Information System's (GIS) Network Analyst module. These journey times by road enabled travel times to be established for these sections, temporal accessibility areas to be plotted from each of the outpatient mental health centres and the number of people included in each accessibility area to be calculated.

Results: The accessibility analysis enabled the sitting of the centres to be evaluated for 2006, a comparison to be made with 2011 (with six new facilities having been set up since 2006) and new locations for the siting of these six new facilities to be proposed.

Conclusions: This study has enabled the optimum territorial locations to be proposed for the six mental health centres created between 2006 and 2011 that would allow travel times to be reduced for the greatest numbers of people possible. It can be stated on the basis of this study that, if territorial criteria had been taken into account, 97,720 inhabitants would have seen their travel times to their nearest mental health centres reduced using the same resources.
\end{abstract}

Received: 4 May 2011

Revised: 18 April 2012

Accepted: 1 June 2012 


\section{Introduction}

Countries such as Spain, where there is a National Health Service (NHS) with universal coverage, provide a wide range of free health care services. However, inequalities continue to be an issue, even in western countries with an NHS model ${ }^{1,2}$.

Territorial accessibility is one of the most important elements that define equity in health care. For this reason, one of the provisions of the 1986 Spanish Health Act lays down that the national health policy should aim to iron out any territorial and social imbalances. This Act also states the criteria for defining health areas in accordance with geographical, socio-demographic, epidemiological and communication features. However, there is no consensus regarding the standard methodology for systematic calculations to be made to enable the territorial siting of new health care services.

It is important to distinguish between "effective" and "territorial" accessibility. "Effective" accessibility refers to a service's opening times, its economic and social availability and people's own funds. However, "territorial" accessibility refers to a service's physical proximity and can be measured using Geographical Information Systems (GIS) ${ }^{3}$. Access to health care services is determined by geographical features, such as distance overland, journey times, the region's geographical features and service availability, as well as socio-demographic factors, such as rurality and ethnicity, income and the state of health care coverage ${ }^{4}$. A service's territorial accessibility refers to the distance between a service and its users' places of residence, and is an essential factor for consideration when siting any planned service. It has thus been demonstrated that the territorial location of health services determines their access and use, two parameters that are inversely related. People who live nearer services are more likely to use them and obtain better outcomes from the care received ${ }^{5}$. Determining where health care facilities should be located is a controversial issue since they are perceived as symbols of local power ${ }^{6}$, especially in the field of mental health, where services are scarce compared to the burden of disease in comparison with services for other health care specialities ${ }^{7}$.

Studies on territorial accessibility to health care facilities have been implemented in a great variety of areas, including hospitals ${ }^{6,8}$, palliative care ${ }^{5,9}$, cancer care ${ }^{4}$ and mental health services ${ }^{10}$.

The territorial location of services is a crucial topic for the health care sector in general terms, but it is especially important for the field of mental health due to the specific features of mental disorders. In the past, mental health patients have been stigmatised, discriminated against and even confined in isolated, remote psychiatric hospitals, which prevented them being included in society. A large number of studies have demonstrated that community care has better effects than hospitalisation, improving the development of the illness and reducing the number of flareups in people who suffer from mental disorders ${ }^{7,11}$. People with mental disorders need to live in the community, near their family and friends. Mental health services are therefore more efficient when they are located in the community $^{12}$. People with mental disorders benefit from their improved quality of life when they are not excluded from society but, instead, take part as citizens in their own right. Improved spatial accessibility has the potential to reduce journey times for mental health patients (enabling them to live nearer the community), for mental health professionals (especially for home visits) and for family members (when they visit their relatives). 
When the responsibility for health care was transferred to the 17 Autonomous Communities or regions, and two autonomous cities, 19 different and independent health care systems were created ${ }^{13}$. This is why an evaluation of the Spanish National Health care system as a whole is impossible, and each of the Autonomous Communities must be assessed individually.

This article presents an analysis of the temporal accessibility by road of the outpatient mental health facilities in Andalusia using the ArcGIS Network Analyst module. Andalusia is the southernmost Autonomous Community in mainland Spain with a population of eight million spread over an area of $87,268 \mathrm{~km}^{2}$. The territory extends almost completely along the southern strip of Spain and borders with Portugal to the west and Morocco to the south. Andalusia is split into eight provinces: Almeria, Cadiz, Cordoba, Granada, Huelva, Jaen, Malaga and Seville. The provincial capitals are among the most highly populated cities in the region along with Jerez and Algeciras (see Figure 1).

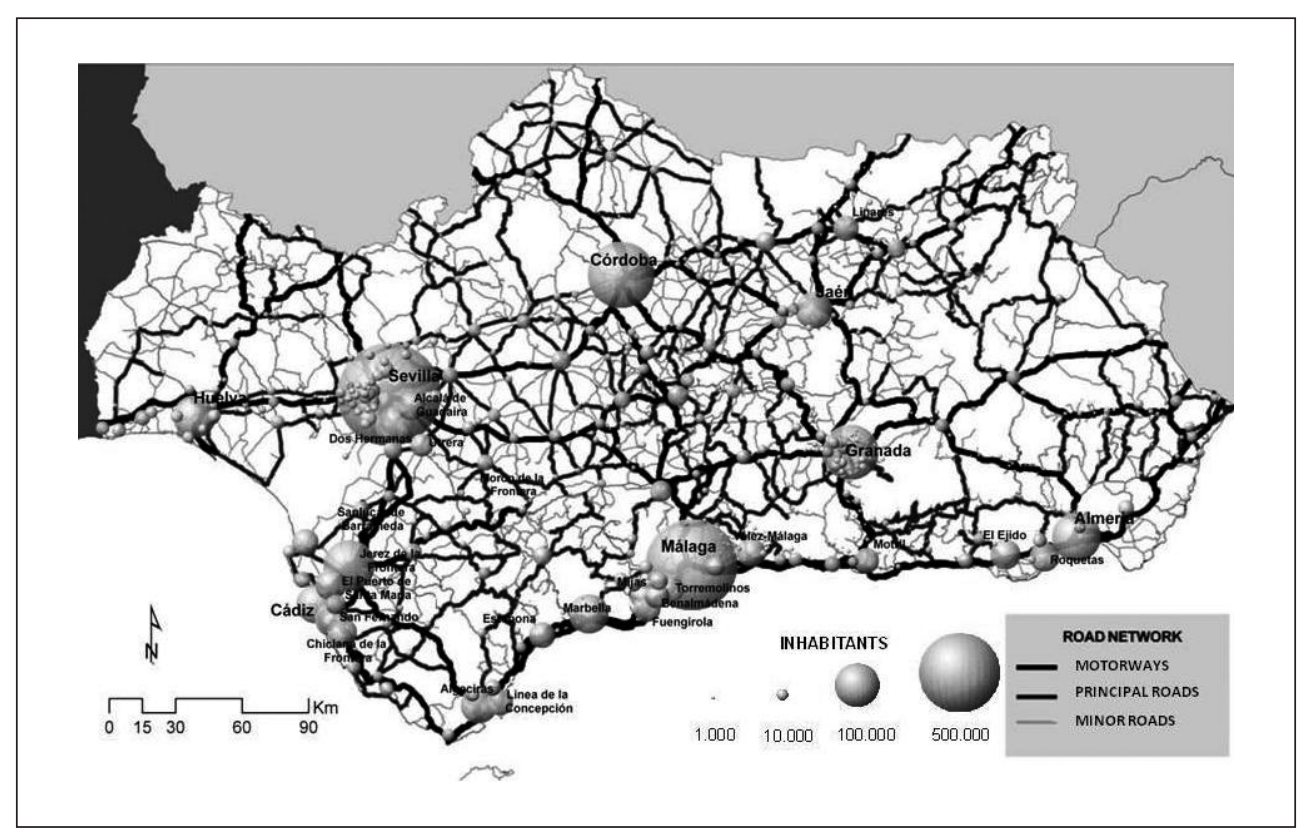

Figure 1. Andalusian territorial population distribution and road network.

\section{Method}

Polygons were created to represent the temporal accessibility by road of each of the outpatient mental health centres and the size of the population within their boundaries was calculated. A number of variables were taken into account to calculate access by road to the outpatient mental health centres: the location of the facilities, the road network (routes, distances, road classification, state of the road surface, sinuosity, etc) and the population (location, age range, etc). 
The first step was to locate the mental health centres using the city centroid in which they were located. On a regional scale, as is the case in Andalusia, the number of facilities in a single city does not affect spatial accessibility. This is why cities like Seville and Malaga, where there is more than one facility, were represented by a single icon.

With regard to the road network, the Andalusian Cartographic Institute's 1:100,000 Digital Map of Andalusia spatial road network coverage (2009) was used and a relative score was awarded to restraints on traffic speed for each section of road. These scores were established on the basis of the official speed limit for each category of road, the specific features of the traffic and the sinuosity of each segment of the road. A sinuosity index was established to calculate speed restraints as follows:

$$
\mathbf{W}=(\text { s\&e / l), }
$$

where $\mathrm{W}$ is the distance in a straight line between the start point and the end point of a given section (s\&e) divided by the actual length of said section (1), with a straight section given a sinuosity score of 1 . This score falls the more the shape of a circumference is approached and the distance between the start point and the end point diminishes, to a point where $\mathrm{W}$ equals 0 .

With respect to the population, a number of inhabitants was assigned to each municipality for 2006 and 2011 respectively, taking the central point of each population centre as a reference point.

Once these centre-points, the population distribution and the travel speed for each section of the road network had all been established, the road network was analysed using the ArcGIS Network Analyst module. This analysis of the road network enabled mini- mum journey times to be established from each of the outpatient mental health centres, and areas of temporal accessibility to be plotted ( $>30$ minutes, from 30 to 60 minutes and $>60$ minutes). Once these accessibility areas had been established the numbers of people in each area were calculated for each of the centres that existed in 2006 and in 2011 (including the six new facilities set up by the Andalusian Health Department between 2006 and 2011), and new optimum locations were proposed for these six new facilities based on geographical criteria using the GIS. What is understood by a centre's "optimum" territorial location is one that enables access by the greatest number of people in the shortest journey time, thus improving temporal accessibility. The suitability of the potential municipalities for relocating these six facilities was assessed; they had to be geographically distant from each other and with no other outpatient mental health facility in their surrounding areas. The suitability of future locations for new mental health services was thus assessed. Each map plotted included three temporal boundaries $(<30$, from 30 to 60 and >60 minutes) which were set as specifically appropriate journey distances for evaluating accessibility to outpatient mental health centres.

The hypothesis that supports the research is based on the idea that the greater the distance to a health centre, the less the pull of the services provided there. Shorter distances to health centres and lower temporal costs for travelling there result in a greater ability to attract people and increased numbers of people tended to. In this way, greater accessibility (lesser physical-geographical difficulty of access) increases the pulling-power of health centres and, consequently, the degree to which users' needs are met, as they can make more frequent and efficient use of them. 


\section{Results}

The temporal accessibility by road of the mental health centres that existed in 2006 was analysed in comparison with accessibility in 2011 by adding the six new facilities at their official locations established by the Andalusian Health Department, and a new location was proposed for each of these six new facilities in keeping with geographical criteria that improve the temporal accessibility of part of the population. Temporal road accessibility areas $(<30$, from 30 to 60 and $>60$ minutes) were plotted round the outpatient mental health centres with a distinction being made between the situations in 2006 (when there were 72 facilities, Figure 2.A) and 2011, when six new facilities had been opened ( 78 facilities, Figure 2.B) at their current official locations and, finally, a proposal was made for the relocation of the six new facilities based on territorial criteria for their optimum locations, whereby a greater percentage of the population would see their journey times reduced (78 facilities, Figure 2.C).

Table 1 presents the population distribution in the three areas of temporal accessibility ( $<30$, from 30 to 60 and $>60$ minutes) by road of the outpatient mental health centres that existed in 2006, in 2011 with the six new fa- cilities in locations according to the official distribution, and with these six facilities in locations according to the territorial criteria proposed for improving temporal accessibility.

Despite the mental health centres being spread across the whole region and providing medical care to the majority of the population, a shortfall can be seen in 2006 in services to the northern mountain areas, which are characterised by low population density and a large proportion of elderly people. Accessibility in these areas had not improved in 2011 despite six new centres being set up. In fact, the setting up of six new centres between 2006 and 2011 did not result in any major changes in temporal accessibility compared to six years previously (2006). However, our geographical criteria-based proposal for the location of these six new facilities results in a major improvement in temporal accessibility compared with the official situation. Indeed, if territorial criteria had been used when the locations of these six new facilities were determined, accessibility would have improved for a large percentage of the population. Accessibility would have improved for $1.16 \%$ of the population (approximately 97,720 inhabitants), who would have moved up from the 3060 minutes band to the 30 minutes band from the nearest outpatient mental health facility.

Table 1

Population distribution in areas of temporal accessibility ( $<30$, from 30 to 60 and $>60$ minutes) by road of the outpatient mental health centres that existed in 2006, in 2011 according to the official distribution, and according to the territorial criteria proposed in Andalusia (Spain)

\begin{tabular}{|c|c|c|c|c|c|}
\hline & $\begin{array}{l}<30 \text { min. } \\
\text { Population } \\
(\%)\end{array}$ & $\begin{array}{l}30 \text { a } 60 \text { min. } \\
\text { Population } \\
(\%)\end{array}$ & $\begin{array}{l}>60 \text { min. } \\
\text { Population } \\
(\%)\end{array}$ & $\begin{array}{l}\text { Total } \\
\text { Population } \\
(\%)\end{array}$ & Year \\
\hline $\begin{array}{l}\text { Outpatient mental health } \\
\text { centres in } 2006(72)\end{array}$ & $\begin{array}{l}7,714,070 \\
(96.72 \%)\end{array}$ & $\begin{array}{l}257,614 \\
(3.23 \%)\end{array}$ & $\begin{array}{l}3,988 \\
(0.05 \%)\end{array}$ & $\begin{array}{l}7,975,672 \\
(100 \%)\end{array}$ & 2006 \\
\hline $\begin{array}{l}\text { Outpatient mental health } \\
\text { centres in } 2011 \text { ( } 78) \text { - Official }\end{array}$ & $\begin{array}{l}8,149,476 \\
(96.74 \%)\end{array}$ & $\begin{array}{l}270,414 \\
(3.21 \%)\end{array}$ & $\begin{array}{l}4,212 \\
(0.05 \%)\end{array}$ & $\begin{array}{l}8,424,102 \\
(100 \%)\end{array}$ & 2011 \\
\hline $\begin{array}{l}\text { Proposed outpatient mental } \\
\text { health centres (78) - Proposal }\end{array}$ & $\begin{array}{l}8,247,196 \\
(97.90 \%)\end{array}$ & $\begin{array}{l}173,536 \\
(2.06 \%)\end{array}$ & $\begin{array}{l}3,370 \\
(0.04 \%)\end{array}$ & $\begin{array}{l}8,424,102 \\
(100 \%)\end{array}$ & 2011 \\
\hline
\end{tabular}


A)

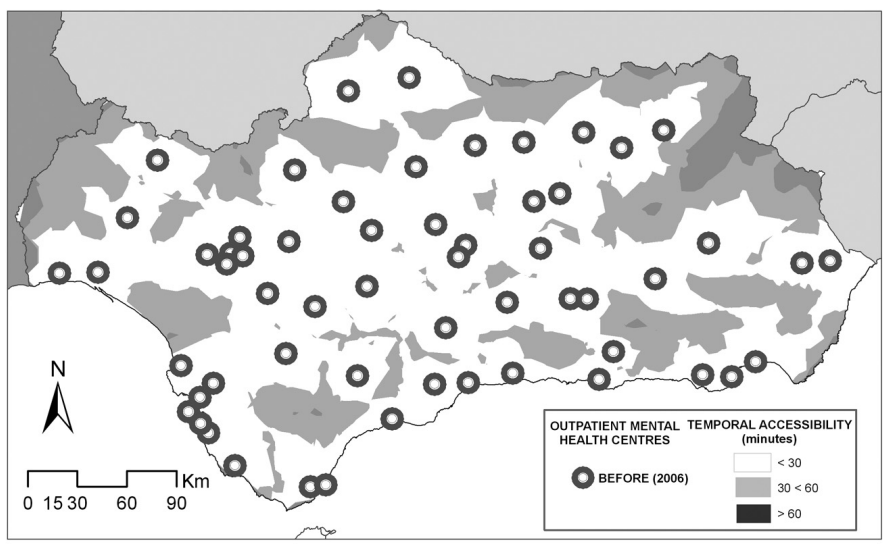

B)

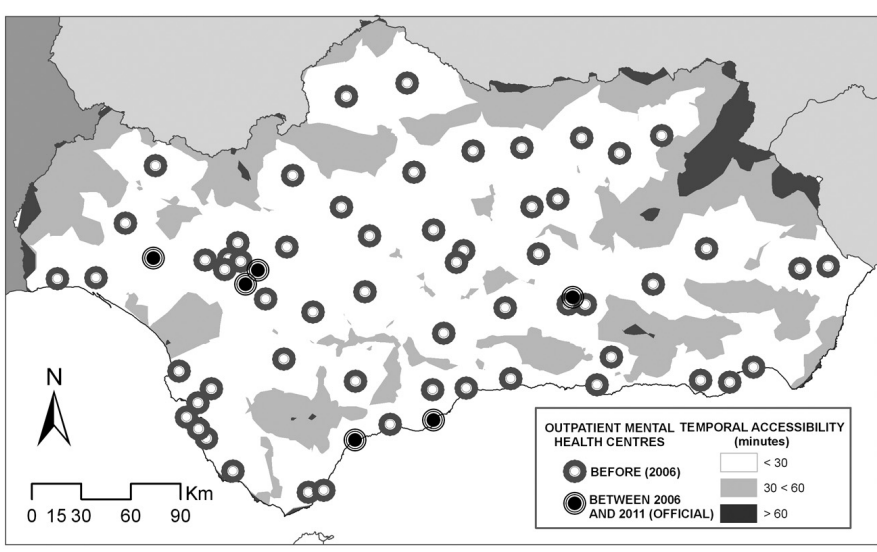

C)

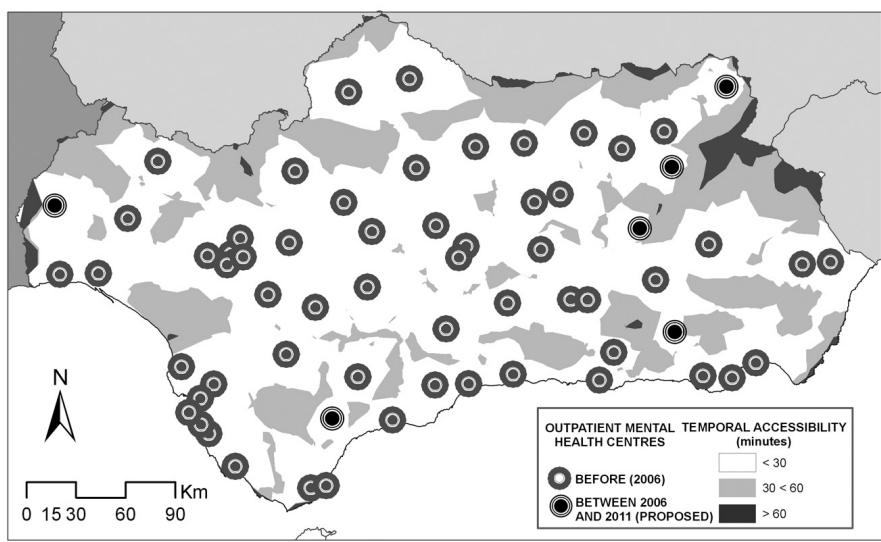

Figure 2. Temporal road accessibility of outpatient mental health centres ( $<30$, from 30 to 60 and $>60$ minutes) in Andalusia (Spain).

A) Situation in 2006.

B) Situation in 2011 with six new facilities located according to the official distribution.

C) Situation in 2011 with these six new facilities located according to territorial accessibility criteria. 


\section{Discussion}

Geographical factors, such as distance, affect the use of mental health services. As a result, an increase in territorial and temporal distance between a person's place of residence and these services means the usage rates decrease $^{14}$. Territorial analysis techniques are useful tools for analysing the distribution of a variable and for explaining factors relating to the availability and appropriate access to health care services ${ }^{15}$.

This study has mainly examined geographical access to outpatient mental health centres. However, apart from territorial aspects, there are other factors, such as the type of medical insurance, patient preferences, socio-economic factors, level of education, waiting lists and the availability of medical care that are barriers to access to medical care that should be analysed along with territorial factors to assess service use.

Increased journey times to medical care services have been linked with a greater risk of mental disorders. Access to specialised services that are not widespread across the territory can be limited, mainly by proximity, which can be measured as travel time ${ }^{4}$.

Individuals with serious mental disorders often have no alternative but to move to another town or city to ensure that they are a reasonable distance from mental health services, which are mainly located in the larger towns and cities. However, patients are often obliged to live far from their own environment, which has a negative impact on the way that their illnesses develop.

In the 2008-2012 Andalusian Integrated Mental Health Plan we find a reference to the need to undertake specific studies on the territorial accessibility of mental health centres as a way of detecting and reducing territori- al inequalities in isolated rural areas. In this way, the need to take into account territorial factors in decision making processes that affect the locations of new mental health resources is mentioned ${ }^{16}$.

A variety of tools have been implemented to calculate the territorial accessibility of health care facilities. It is possible to define accessibility areas according to the places of residence of patients tended to ${ }^{17}$ and establish the accessibility areas of the specific medical care facilities ${ }^{10}$. Temporal distances appear to be more interesting than physical distances as they include information regarding journey features and the condition of the transport infrastructure. The changes and technical improvements in transport infrastructure are capable of modifying the ease and speed with which people are able to access medical care services. However, not all regions are organised in the same way in territorial terms, which leads to disparities and inequalities which can be reduced when an integrated management and planning system is implemented. Geographical Information Systems (GIS) are suitable tools for detecting the areas with the greatest shortfalls in certain services ${ }^{18}$.

As has been shown in this study, the greater part of the population lives near one or other of the outpatient mental health centres, although a number of inhabitants still live a certain distance away and only have limited access to mental health care. The analysis of the territorial accessibility of mental health centres has been seen to be useful for detecting peripheral and neglected areas. These findings show that the locations of the new services created between 2006 and 2011 were chosen without taking into account any criteria for territorial equity. However, it has been demonstrated that it is possible and viable to reduce temporal distances and territorial inequalities, using the same resources, if geographical analysis methods are used 
for their location. GIS tools and methods could be included among mental health system management and planning tools.

\section{Conclusion}

The information produced has enabled us to detect and propose optimum locations for the new mental health centres established during the 2006-2011 period. On the basis of this study it can be stated that if territorial criteria had been taken into consideration, 97,720 inhabitants would have seen their journey times to the nearest mental health centre reduced using the same resources. The proposed methodology could support the work done by managers and planners when deciding on where future mental health care centres are to be located.

The initial hypothesis has been demonstrated; reduced distances and temporal costs for travelling to health centres result in these having a greater pulling-power and in an increase in the number of people tended to, and GIS is an effective method for determining their optimum locations.

\section{Acknowledgements}

This article is the result of the Spanish National R\&D\&i Scientific Research "Desarrollo de un modelo para optimizar el acceso y uso a los servicios de salud mental en España (MODEMENT)" (Development of a model to optimise access to mental health services and their use) Project CSO200913268 , financed by the Spanish Ministry of Science and Innovation (2010-2012) and EU ERDF funds. We are grateful to the Andalusian Health Department's Mental Health Pro- gramme, and, especially, to G. Fernandez and P. Cubillanas for the information that they supplied on the availability and territorial locations of mental health resources in Andalusia (Spain).

\section{References}

1. Borrell C, Pasarín MI. The study of social inequalities in health in Spain: where are we? J Epidemiol Community Health 1999; 53: 388-389.

2. Garrido-Cumbrera M, Borrell C, Palència L, Espelt A, Rodríguez-Sanz M, Pasarín MI, et al. Social class inequalities in the utilization of health care and preventive services in Spain, a country with a national health system. Int J Health Serv 2010; 40(3): 525-542.

3. Joseph E, Philips D. Accessibility and Utilization-Geographical Perspectives on Health Care Delivery. London: Harper \& Row Ltd.; 1984.

4. Onega T, Duell EJ, Shi X, Wang D, Demidenko E, Goodman D. Geographic access to cancer care in the U.S. Cancer 2008; 112(4): 909-918.

5. Cinnamon J, Schuurman N, Crooks VA. A method to determine spatial access to specialized palliative care services using GIS. BMC Health Serv Res 2008; 30(8): 140.

6. Brabyn L, Skelly C. Modeling population access to New Zealand public hospitals. Int J Health Geogr 2002; 1(1): 3 .

7. Saxena S, Sharan P, Garrido-Cumbrera M, Saraceno B. World Health Organization's Mental Health Atlas 2005: implications for policy development. World Psychiatry 2006; 5(3): 179-184.

8. López Lara L, Garrido Cumbrera M. Análisis de la accesibilidad hospitalaria por carretera en Andalucía mediante Sistemas de Información Geográfica. In: Lopez Lara E, Miranda Bonilla J, Posada Simeon JC, Navarro Luna J, Garcia Gomez A, editors. Servicios y Transportes en el desarrollo territorial de España. Seville: El Monte; 2003; p. 405-420.

9. Cinnamon J, Schuurman N, Crooks VA. Assessing the suitability of host communities for secondary palliative care hubs: a location analysis model. Health \& Place 2009; 15(3): 822-830.

10. Garrido Cumbrera M, Salinas JA, Almenara J, Salvador L. Atlas de Salud Mental de Andalucía 2005. Seville: Ministry of Health. Government of Andalusia; 2007. 
11. Jacob KS, Sharan P, Mirza I, Garrido-Cumbrera M, Seedat S, Mari JJ, et al. Mental health systems in countries: where are we now? Lancet 2007; 370(9592): 1061-1077.

12. World Health Organization (WHO). World Health Report. The world health report 2001 - Mental Health: new understanding, new hope. Geneva: World Health Organization; 2001.

13. Rico A, Costa-Font J. Power Rather Than Path Dependency? The Dynamics of Institutional Change under Health Care Federalism. J Health Polit Policy Law 2005; 30(1-2): 231-252.

14. Bürgy R, Häfner-Ranabauer W. Utilization of the psychiatric emergency service in Mannheim: ecological and distance-related aspects. Soc Psychiatry Psychiatr Epidemiol 1998; 33(11): 558-567.

15. Moreno B, García-Alonso CR, Negrín Hernández MA, Torres-González F, Salvador-Carulla L. Spatial analysis to identify hotspots of prevalence of schizophrenia. Soc Psychiatry Psychiatr Epidemiol 2008; 43(10): 782-791.

16. Ministry of Health of Andalucía. II Comprehensive Mental Health Plan for Andalucía 2008-2012. Seville: Ministry of Health of Andalusia; 2008. http://www.juntadeandalucia.es/servicioandaluzdesalud/library/plantillas/externa.asp?pag=/contenidos/gestioncalidad/PISMA_08_ENGLISH.pdf

(Accessed Feb. 2012).

17. Pineault R, Daveluy C. La planificación sanitaria: conceptos, métodos y estrategias. Madrid: Masson; 1989.

18. Garrido-Cumbrera M, Almenara-Barrios J, LòpezLara E, Peralta-Sàez JL, Garcìa-Gutierrez JC, SalvadorCarulla L. Development and spatial representation of synthetic indexes of outpatient mental health care in Andalusia (Spain). Epidemiol Psichiatr Soc 2008; 17(3): 192-200.

Author for correspondence: Marco Garrido-Cumbrera, $\mathrm{PhD}$ Departamento de Geografía Universidad de Sevilla C/ Doña María de Padilla s/n 41013 Seville (Spain) Tel.: +34 954551372 Fax: +34 954556988

E-mail: mcumbrera@us.es 